\title{
Customers' preferences and willingness to pay for a future dengue vaccination: a study of the empirical evidence in Vietnam
}

This article was published in the following Dove Press journal:

Patient Preference and Adherence

\section{Trung Quang Vol,* Quang Vinh Tran ${ }^{1, *}$ Nam Xuan Vo \\ 'Department of Pharmacy Administration, Faculty of Pharmacy, University of Medicine and Pharmacy at Ho Chi Minh City, Ho Chi Minh City 700000 , Vietnam; ${ }^{2}$ Department of Social, Economic and Administrative Pharmacy, Faculty of Pharmacy, Mahidol University, Bangkok I0400, Thailand \\ *These authors contributed equally to this work}

Background: Dengue was endemic to Vietnam. Due to the lack of a readily available remedy, dengue vaccines (DV) have been used elsewhere to cure the disease. However, introducing DV in Vietnam has met resistance from society and the government, influencing decisions about willingness-to-pay (WTP) and other pharmacoeconomic studies. This research aimed to evaluate the extent to which Vietnamese customers would be willing to pay to vaccinate themselves and their children, if any at all, against dengue.

Materials and methods: This was a cross-sectional interview-based research. Contingent valuation method, combined with the bidding technique and several open-ended questions, were used to obtain the maximum WTP values for six hypothetical scenarios of two types of DV (60\% efficacy for 10 years, “Type 1" vs 90\% efficacy for 20 years, “Type 2").

Results: The median WTP per adult for Type 1 and Type 2 DV were US\$130.34 and US\$217.39, respectively. The median WTP rates per parent for their own vaccination were US\$86.96 (Type 1) and US\$156.52 (Type 2), for their children vaccination costs were US\$108.70 (Type 1) and US\$195.65 (Type 2). Five factors affected the WTP rates: monthly income, marital status, area, locality and level of education.

Conclusion: The WTP rates for DV were high, supporting the introduction of DV in Vietnam. Keywords: customer, dengue fever, dengue vaccine, Vietnam, willingness to pay (WTP)

\section{Introduction}

Dengue fever (DF) is a global viral disease, and it is estimated that it annually affects some 390 million people worldwide. ${ }^{1}$ Approximately, 50\% of the world's population live in areas that are at risk of the disease, ${ }^{2}$ which poses a significant public health threat in many parts of the tropics and subtropics. ${ }^{3}$ With a yearly average of 34.3 cases per 1,000 people, Southeast Asia tends to record the highest dengue incidence rates. ${ }^{4}$ Vietnam observed 18,432 cases with 12 deaths in 2015, which jumped to 48,798 cases with 14 deaths in the first 7 months in $2016 .{ }^{5}$ Due to the lack of readily available medications, fluid therapy is considered the only management procedure for dengue infection..$^{6,7}$

Vaccination has been identified as an effective preventive and long-term control method to contain not only dengue fever but several other infectious diseases. ${ }^{8}$ Certain promising dengue vaccines (DV) have recently been developed and tested. ${ }^{9}$ By the end of 2016, DVs had introduced in six countries, which are Mexico, Brazil, the Philippines, Costa Rica, El Salvador and Paraguay. ${ }^{10}$ However, the scope as well as the full protective duration of the vaccine require more investigation. World Health Organization (WHO) approved the indication from this first vaccine for individuals aged nine and above,
Department of Pharmacy Administration, Faculty of Pharmacy, University of Medicine and Pharmacy at Ho Chi Minh City, 4 I-43 Dinh Tien Hoang Street, Ben Nghe Ward, District I, Ho Chi Minh City 700000 , Vietnam

Tel +84283829 564I ext I 23

Fax +842838225435

Email voquangtrungdk@gmail.com 
depending on the license of each authority. A vaccine's development cycle from an idea to a product involves several challenges. Underutilization, for example, is a multifaceted problem that stems from prejudices against vaccination, customers' mistrust and misunderstanding, and competition from other social priorities, such as poverty alleviation and economic growth. Another challenge involves the lack of incentives for innovating new vaccines, which originates from the difficulty of balancing fixed costs and the pressures that public sector payers put on prices. These challenges are complex and counterproductive, requiring the cooperation of key stakeholders. ${ }^{11}$ When a vaccine comes on the market, it would not immediately lead to customer acceptance. Previous studies illustrate how certain factors influence the customers' willingness to pay (WTP) for DV, demonstrating the obstacles in the path of adopting DV in endemic areas. ${ }^{12-14}$

As far as dengue vaccination is concerned, governments are facing complex questions as to how they can optimize potential vaccination programs, given the national budget constraints. These issues have caused WTP and other pharmacoeconomic studies to await decision-making. ${ }^{15-17}$ WTP is defined as the maximum price that an individual is willing to pay to procure certain goods, services and healthcare programs. ${ }^{17}$ Contingent valuation method (CVM) is known to be the preferable approach to access healthcare products' WTP. ${ }^{18-27}$ Thus far, only one study has assessed household WTP for DV in a province in the middle of Vietnam; ${ }^{15}$ however, no study has yet been conducted on DF epidemics with data that can be generalized to the Vietnamese settings. Due to the regional cultural and economic variations, it is important to obtain WTP estimates from the many populations in Vietnam.

This article uses CVM to evaluate the extent to which Vietnamese customers are willing to pay to have themselves and their children vaccinated against dengue. It is hoped policy-makers will used our findings to inform their decisions as to how they can best promote DV in Vietnam.

\section{Materials and methods}

A cross-sectional survey of communities was performed from June to October 2018 in 32 southern provinces in Vietnam, with an estimated total population of 49,025,500 in $2017 .{ }^{28}$ The study asked two questions:

1. How are the participants' demographic and socioeconomic characteristics associated with their WTP for DV?

2. How could diverse efficacies and protective duration influence their WTP for DV?

\section{Sampling}

A convenience sampling method was used to invite individuals to participate in an interview. These people were regular passers-by in the major boulevards, nearby parks, markets and coffee shops. Participants were recruited if they met all the criteria shown in Figure 1. WTP for six scenarios was investigated. Participants were divided into two groups: 1) adults with no children; and 2) parents with at least one child. Following the definition of the United Nations Convention on the Rights of the Child, in this study "child" refers to a human being who is below the age of $18 .^{29}$ The study required a minimum of 655 adults and 232 parents with a two-side 0.05 significance. ${ }^{30}$ Assuming the possibility of $20 \%$ missing data, 1,064 questionnaires were released. Figure 1 illustrates the complete recruitment process, including the inclusion criteria and the scenarios as well.

Ten undergraduate students of the University of Medicine and Pharmacy at Ho Chi Minh City attended a 7-day training on interviewing techniques. After further training in the enumeration and administration of the survey method, they were able to handle emerging data during the interviews. An arrangement was made to distribute these interviewers to all southern provinces of Vietnam.

The interview began by eliciting the participants' demographic information, source of DV information they accessed, and their attitude towards vaccination practice. Acceptance of vaccine was measured by asking participants to use a single-dose injection to vaccinate a hypothetically ideal DV against four types of DV. The vaccine was supplied by the government free of charge and had no adverse effects. The factors that influenced their acceptance of vaccine were then explored. A 5-point Likert scale was used, ranging from 1 (strongly disagree) to 5 (strongly agree), with the midpoint being "undecided." Answers that equaled 4 or 5 were classified as "agree" or "accept."

\section{WTP measurement}

The module on WTP for DV began by describing DF and its consequences to ensure that all the participants had the same information. The participants were introduced a hypothetical DV with typical attributes based on findings from previous clinical trials on possible DV. ${ }^{31-41}$ A figure was also designed that distinctly explained the efficacy of the vaccine to make sure that the interviewees fully understood the information given.

The iterative bidding technique was used to explore individual WTP, followed by a dichotomous-choice question and a final open-ended question about the participants' 


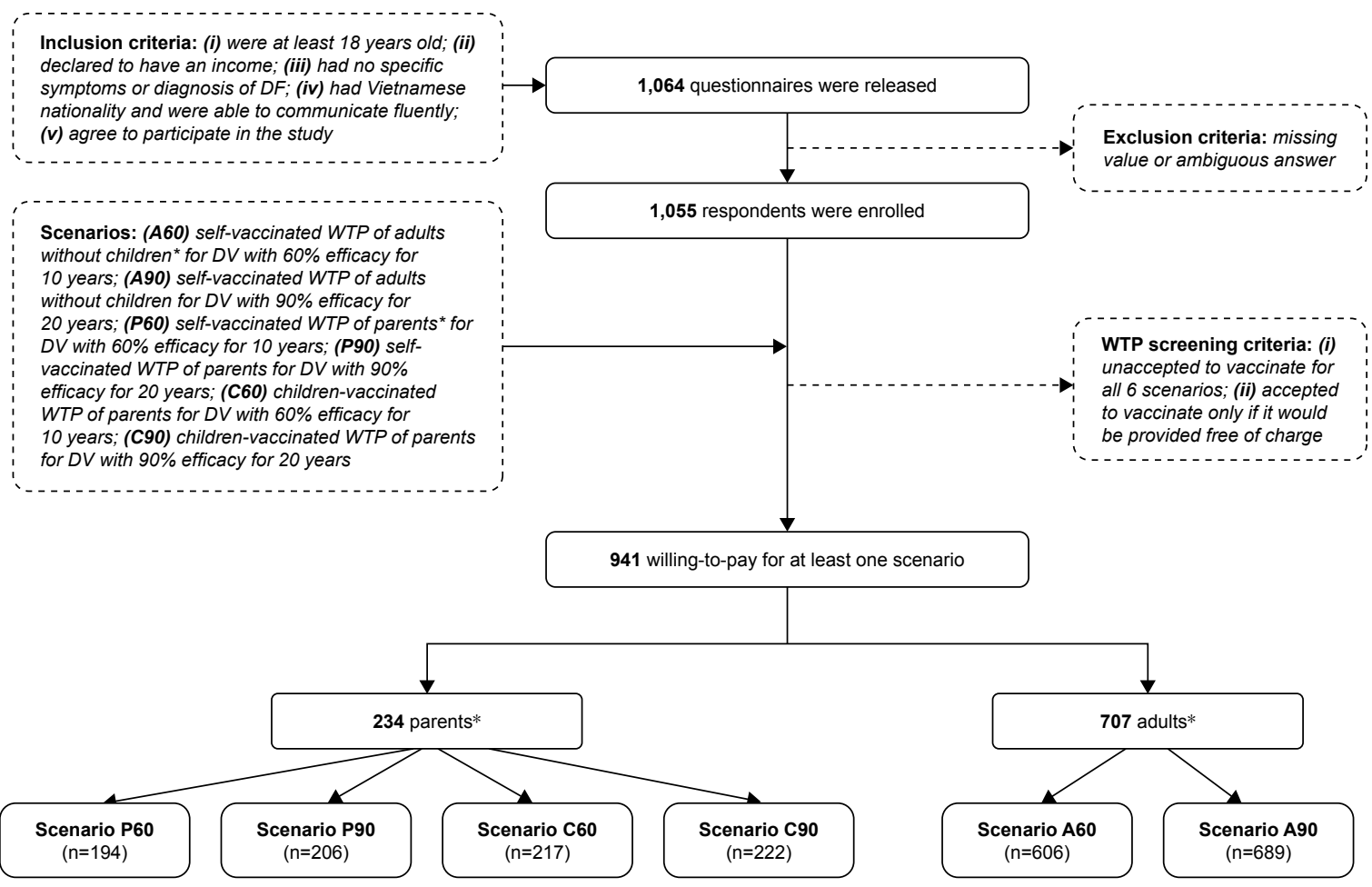

Figure I Flow chart of data collection.

Notes: *Parents are defined as those who have at least one child who is under 18. Adults are defined as those who have no children.

Abbreviations: WTP, willingness to pay; DV, dengue vaccine; DF, dengue fever.

maximum WTP for themselves and their children (if any). The participants were offered the DV at a starting protective efficacy of $60 \%$ for 10 years at US $\$ 234.78$ for the three-dose scheme (this figure is equivalent to 5.4 million Vietnam Dong based on the June 2018 exchange rate; US\$ will be used hereafter). For those who accepted the price, the bid was raised to US\$273.91. If this amount was again accepted, the bid would be raised to US\$313.04. At this level, the participant was asked about his/her maximum WTP for the US\$313.04 bid, irrespective of their acceptance or rejection. Conversely, if the participants rejected the starting bid of US\$234.78, the bid was lowered to US\$195.62, then to US $\$ 156.52$ if he/she rejected it, and finally was asked about the maximum WTP.

Due to a relatively low efficacy for an applicable vaccination program of the $60 \%$-efficacy-in-10-years DV, the participants were subsequently introduced to a desirable DV with a protective efficacy of $90 \%$ for 20 years. The bidding game was repeated for the second DV. In addition, the same method was used if the participants had children to evaluate the WTP for both themselves and their sons/daughters. Interviewees were reminded of their budget constraint before answering the dichotomous-choice questions. Figure 2 summarizes the bidding game techniques.

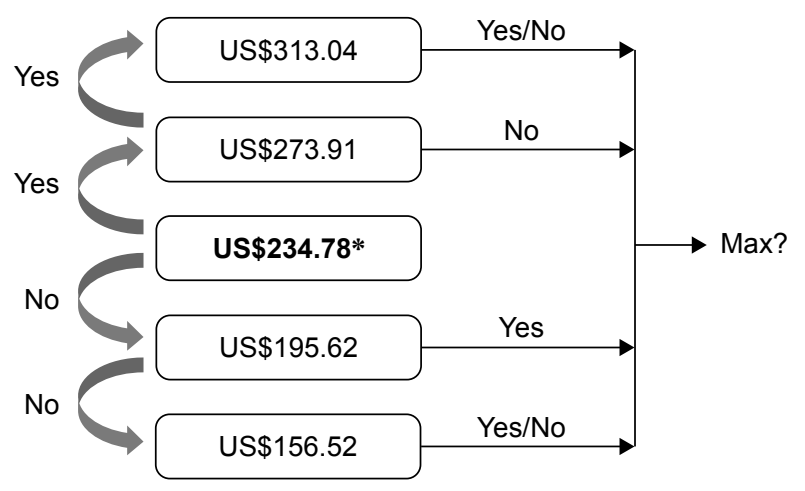

Figure 2 Iterative bidding technique used to explore WTP for DV.

Notes: *Exchange rate: US\$I=VND23,000. Scenario: "Good morning/afternoon. I am_from the University of Medicine and Pharmacy at Ho Chi Minh City. I am inviting you to participate in a study that estimates the WTP for DV. First, let me give you some basic information about the DF. Dengue is a mosquito-borne viral infection. Four serotypes of the virus that cause dengue are DEN-I, DEN-2, DEN-3 and DEN-4. Recovery from infection by one DV provides lifelong immunity against that particular serotype. However, cross-immunity to the other serotypes after recovery is only partial and temporary. Subsequent infections by other serotypes increase the risk of developing severe dengue.' Cost of DF treatment in Vietnam is estimated at US\$139.3 \pm 61.7 per case. ${ }^{47}$ Fortunately, DV has been developed and tested in some countries around the world, but not in Vietnam yet. Each vaccine requires administering three shots over I year, which is available in your local medical center or hospital. Six months for re-vaccination is required to restore protection, unless the effectiveness wears off. All vaccines are safe but may cause soreness, mild fever, headache, malaise, myalgia, and swelling at the injection site. ${ }^{10} \mathrm{We}$ would like to ask whether you agree to get the DV, and if yes, how much you are willing to pay for each of these following DV scenarios to protect yourself (and your under-18-year-old children if you have any) based on our questions below. Please note that your budget is limited, as there is no financial support from health insurance offices or the government."

Abbreviations: WTP, willingness to pay; DV, dengue vaccine; DF, dengue fever; VND, Vietnam Dong. 


\section{Statistical analysis}

The maximum price that the participants stated in the openended question was considered as their WTP for a particular scenario. Prior to the normal distribution test, outliers were eliminated using boxplot and Q-Q plot methods. The ShapiroWilk test resulted in an abnormal distribution; WTP therefore was presented in median with an interquartile range. The median data among groups of participants were compared using the nonparametric tests (Wilcoxon rank-sum test for two independent groups and Kruskal-Wallis test for more than two groups) at the significance level of 5\%. Spearman's Rho was used to determine WTP correlation for different scenarios. Statistical analysis was performed using Microsoft Excel 2016 for Windows ${ }^{\circledR}$ with the Analysis Toolpak add-ins.

\section{Ethical considerations}

Ethical approval for the contingent valuation study and survey questionnaire was obtained from the Science Research Committee of the Faculty of Pharmacy, University of Medicine and Pharmacy in Ho Chi Minh City. Participation was voluntary and anonymous. The participants were asked to sign an informed consent form prior to enrollment.

\section{Results}

Of a total of 1,055 participants, 941 were willing to pay for at least one scenario. Table 1 shows the demographic information of the participants. Figure 3 displays the source of information about DF as well as the factors that influenced participants' acceptance of vaccination.

With regard to the median WTP of six scenarios, Figure 4 demonstrates the cumulative percentage of individuals willing to pay for DV. Figure 5 shows the group tests that resulted in statistically significant difference of medians. Significant Spearman's rank correlation coefficients between pairs of WTP are illustrated in Figure 6.

\section{Discussion}

This study investigated adults', parents' and children's WTP for six vaccination scenarios with two types of DV: 1) $60 \%$ efficacy for 10 years - hereafter referred to as "Type 1"; and 2) $90 \%$ efficacy for 20 years - hereafter referred to as "Type 2." The median WTP rates per adult for Types 1 and 2 DV were US\$130.34 and US\$217.39, respectively. The median WTP rates per parent groups for their self-vaccination were US\$86.96 and US\$156.52, and for their children's vaccination were US\$108.70 and US\$195.65, respectively for Types 1 and 2 DV (Figure 4). The findings from this study
Table I Demographic characteristics of I,055 respondents

\begin{tabular}{|c|c|c|}
\hline Variable & $\mathbf{n}$ & $\%$ \\
\hline \multicolumn{3}{|l|}{ Age (years) } \\
\hline Median (QI-Q3) & $27(22-38)$ & \\
\hline Min-Max & $|8-8|$ & \\
\hline Male & 410 & 38.86 \\
\hline Have children under 18 & 260 & 24.64 \\
\hline Bachelor's degree and higher & 419 & 39.72 \\
\hline Currently working & 959 & 90.90 \\
\hline Ho Chi Minh City & 686 & 65.02 \\
\hline Urban & 781 & 74.03 \\
\hline Single/widowed/divorced & 618 & 58.58 \\
\hline \multicolumn{3}{|l|}{ Income (GDP per capita per month; US\$195.26) ${ }^{46}$} \\
\hline$<1$ & 380 & 36.02 \\
\hline $\mathrm{I}-2$ & 390 & 36.97 \\
\hline$\geq 2$ & 263 & 24.93 \\
\hline NA & 22 & 2.08 \\
\hline History of DF & 776 & 73.55 \\
\hline Self-reported & 264 & 25.02 \\
\hline Know someone else who has history of DF & 656 & 62.18 \\
\hline $\begin{array}{l}\text { Agree to get vaccinated by a hypothetically } \\
\text { ideal } \mathrm{DV}^{\mathrm{a}}\end{array}$ & 870 & 82.46 \\
\hline \multicolumn{3}{|l|}{ Agree with the following statements ${ }^{a}$} \\
\hline $\begin{array}{l}\text { "Vaccination is important for disease } \\
\text { prevention" }\end{array}$ & 917 & 86.92 \\
\hline "Vaccines are safe" & 590 & 55.92 \\
\hline $\begin{array}{l}\text { “You always meet your children's vaccination } \\
\text { schedule” }\end{array}$ & 804 & 76.21 \\
\hline
\end{tabular}

Notes: ${ }^{\text {a }} 5$-point Likert scale ranging from I = "strongly disagree" to $5=$ "strongly agree" was used. Those whose answers equal 4 or 5 were classified as "agree" or "accept."

Abbreviations: DF, dengue fever; DV, dengue vaccine; GDP, Gross Domestic Product; NA, Not available (unknown/not want to answer); QI, quartile $25 \%$ percentile; Q3, quartile $75 \%$ percentile.

suggest very high estimates compared to those reported in previous studies. ${ }^{15-17,42,43}$ The latest study in Vietnam ${ }^{15}$ estimated the median WTP rate per household at US\$26.4 for three doses (around US\$32.25 in 2018). WTP rates for DV vary between US $\$ 1.94$ in Indonesia $(2013)^{16}$ and US $\$ 68.80$ in Thailand (2012).$^{15}$ These variations may be explained by differences in the hypothetical DV scenarios, data collection processes, and methods of statistical analysis.

Most studies, including this study, have reported WTP as medians. The median is the breakdown point that separates the higher half from the lower half of the data set. The median value of US\$195.65 means that $50 \%$ of the interviewees reported the maximum value of WTP as equal to or less than US\$195.65. The skewed distribution renders this value significant in WTP analysis, justifying its use. However, it does not represent an estimated average value of WTP.

This study explored five factors that influenced WTP for DV (Figure 5). Residents in towns and cities have a higher income than those in rural areas. Ho Chi Minh City is the largest economic center in Vietnam and makes a substantial 


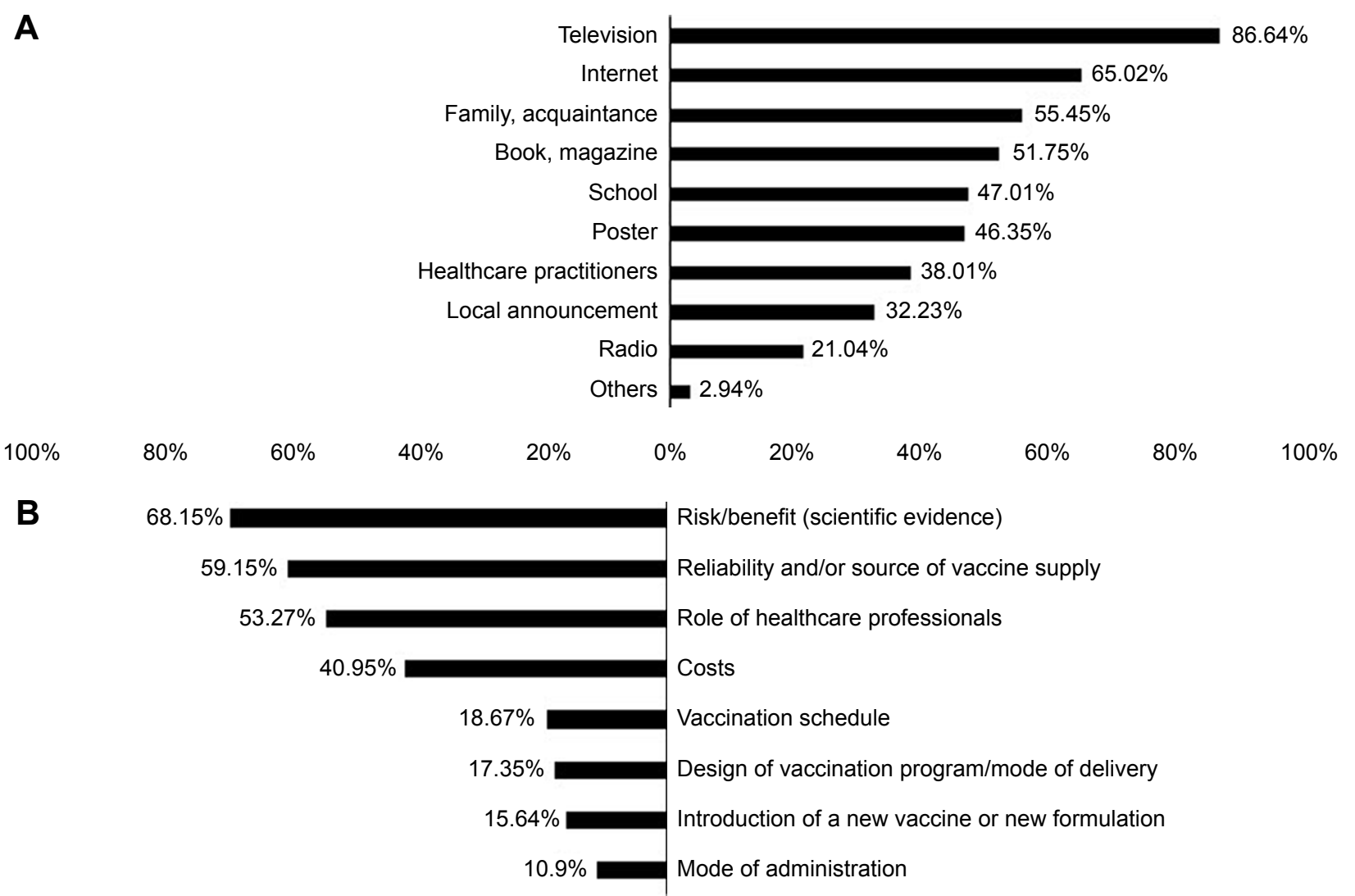

Figure 3 Source of DF information (A), and factors that influenced the acceptance of vaccination $(\mathbf{B})(\mathrm{N}=\mathrm{I}, 055 ; \%)$. Abbreviation: DF, dengue fever.

contribution to the national GDP, which accounts for the participants' higher WTP for DV. Highly educated individuals showed a greater tendency to pay more for DV, not least because they may be well aware of the danger of getting dengue and the importance of preventing it. In addition, the high Spearman's correlation coefficients suggest that the more a parent is willing to pay for self-vaccination, the more he/she will pay for the children; similarly, the more an individual is willing to pay for Type $1 \mathrm{DV}$, the more they will pay for Type 2 .

Regarding the DF information, television and Internet were found to be the most popular sources. This is a corollary of the strong development of multimedia and digital materials in Vietnam in the past decade. It is highly recommended that television channels and web pages be used for any campaigns that intend to raise public awareness about DF and DV.

Of 1,055 participants, 114 (10.80\%) individuals did not express willingness for any scenarios. This includes those who did not accept vaccination as well as those who did but only when the DV was provided free. This percentage is close to that observed in Brazil (8.48\%) and Indonesia (12.50\%). This high percentage could be explained by the factors that influenced the acceptance for vaccination (Figure 3). Most of the participants considered safety rather than cost prior to their decision for vaccination, especially the parents. In Vietnam, the anti-vaccine movement since the crisis of 2017 has eroded consumer confidence in universal vaccination programs. Despite the government's efforts, such mentalities continue to be detrimental to the healthcare systems. DV, like other vaccination programs, is most likely to suffer the same fate when officially introduced in Vietnam.

The CVM is a very common approach that uses hypothetical questions to estimate the monetary value for non-market goods and services. Unlike other forms of CVM, bidding game is time-consuming but is best conducted via a face-to-face interview. ${ }^{44}$ This approach gives useful insights about a person's maximum WTP. The potential bias of the bidding method is called "starting point bias" or "anchor bias." This bias holds that WTP values can fluctuate depending on how low/high the first bid is. That might be the most rational reason for the difference in medians of WTP among various studies. The starting bid in this study was US\$234.78 - much higher than those in previous studies (eg, US\$2.9 in Vietnam, US\$0.73 in 

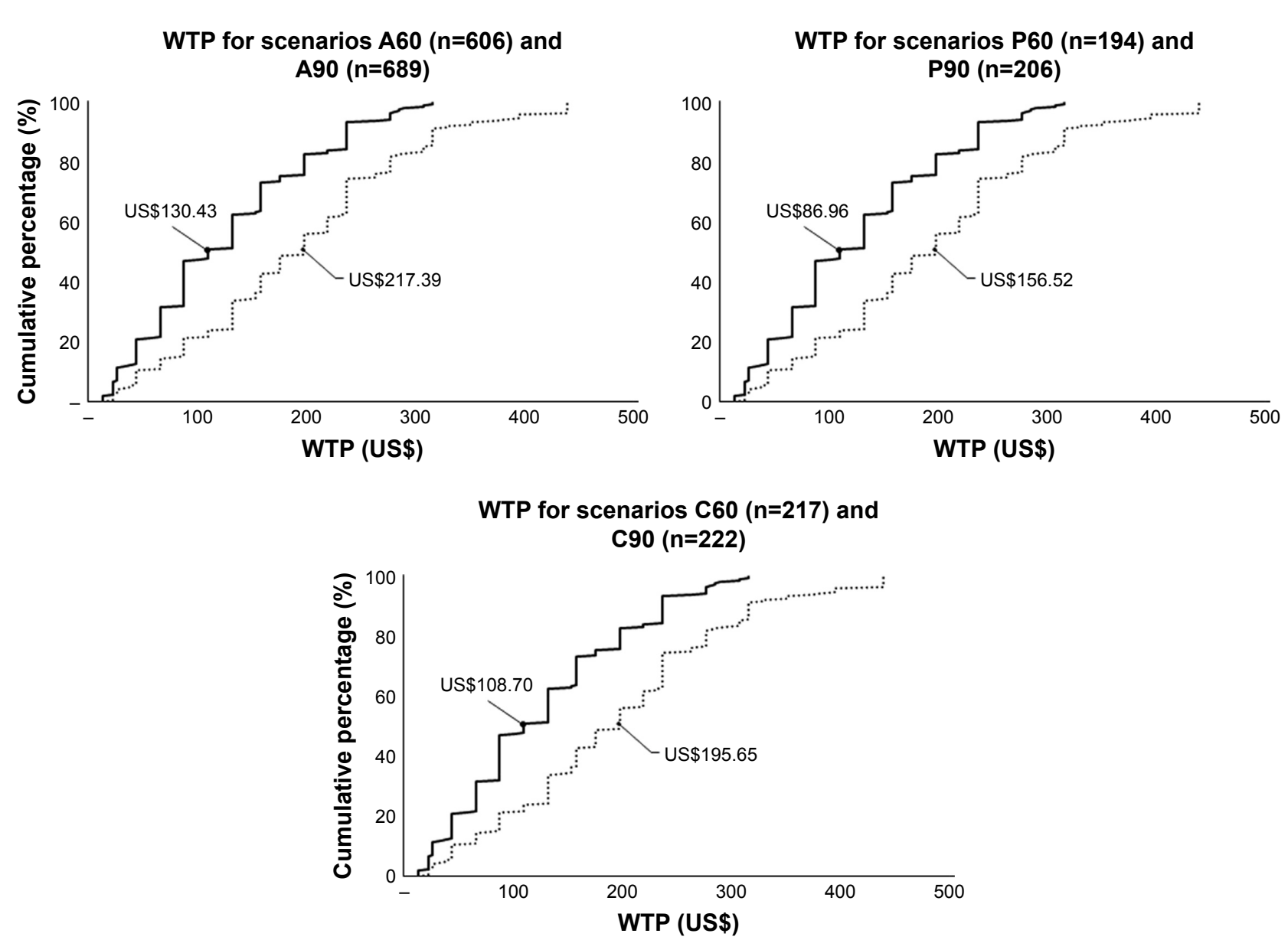

WTP for DV with $60 \%$ efficacy for 10 years

WTP for DV with $90 \%$ efficacy for 20 years

Figure 4 Cumulative percentage of individuals WTP for DV scenarios with medians reported.

Abbreviations: DV, dengue vaccine; WTP, willingness to pay.

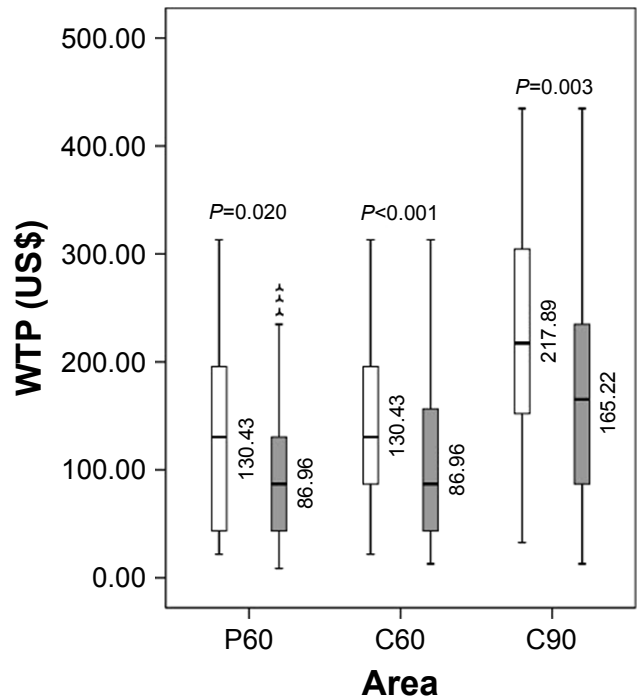

$\square$ HCMC $\square$ Others

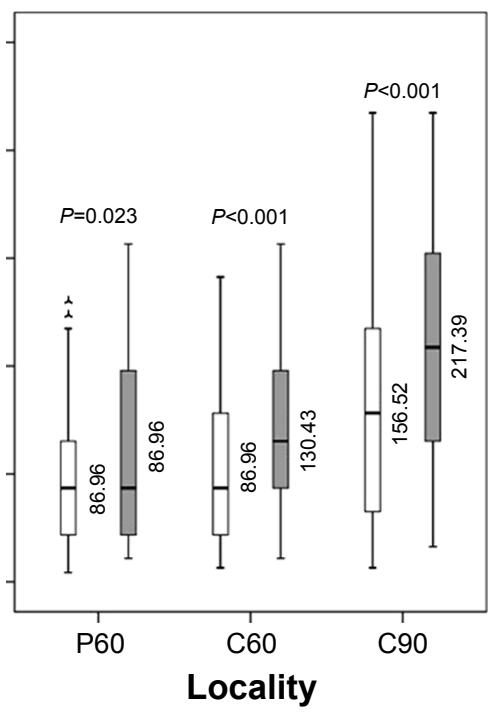

$\square$ Rural $\square$ Urban

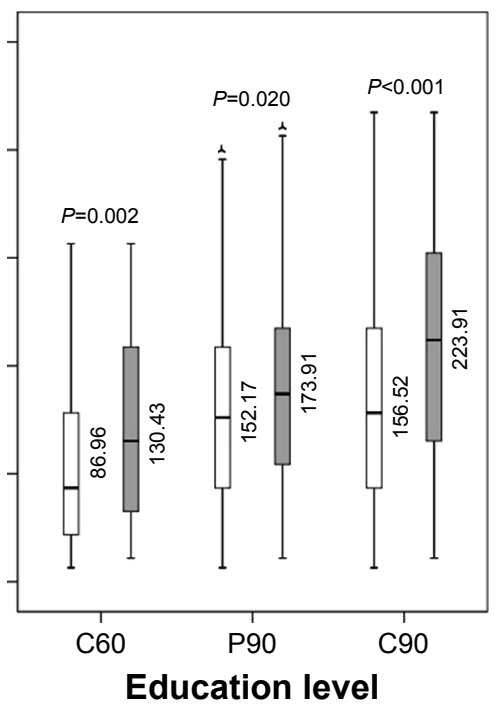

$\square$ Lower than bachelor degree $\square$ Bachelor degree and higher

Figure 5 (Continued) 


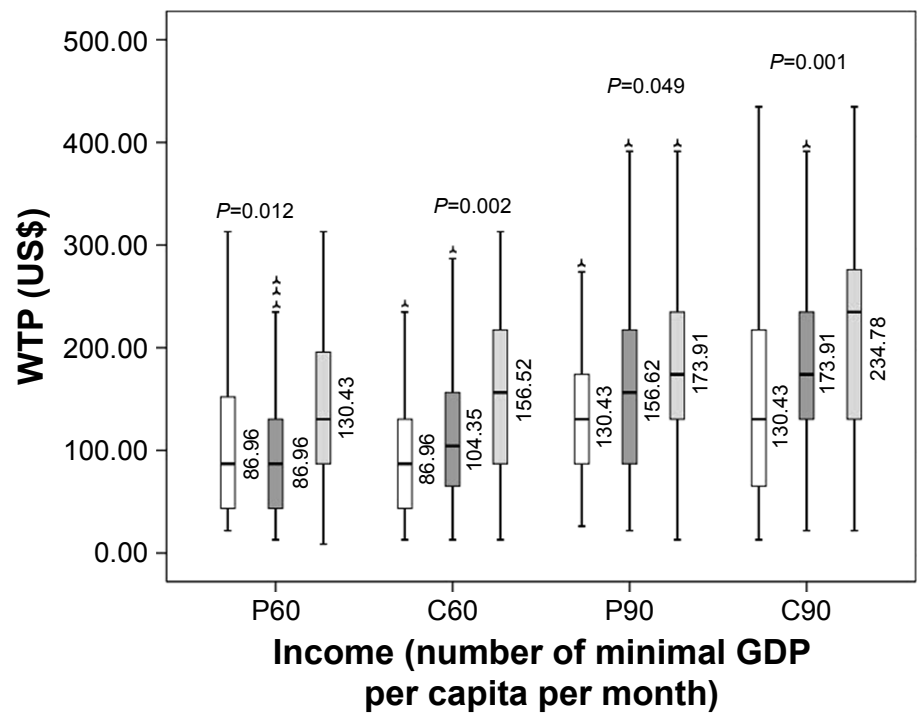

$\square<1 \square 1$ to $2 \square \geq 2$

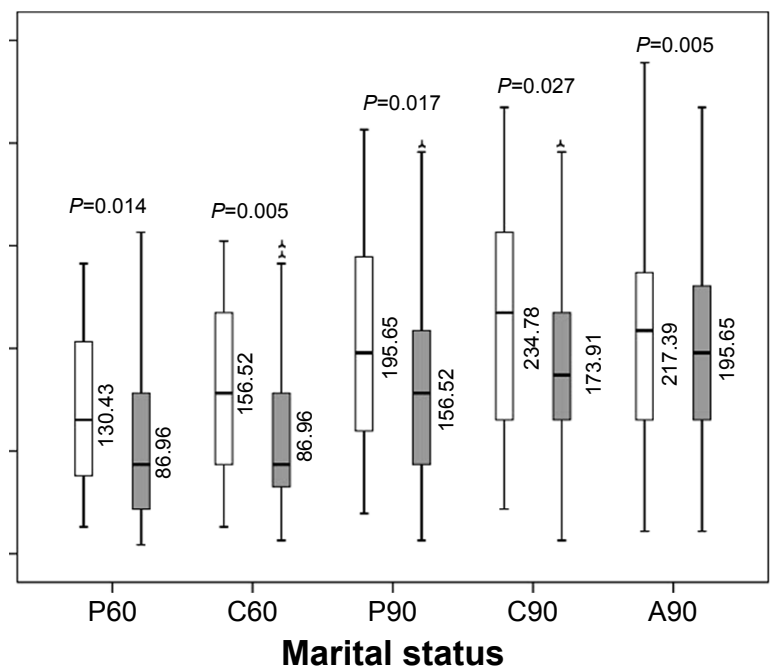

$\square$ Single/widowed/divorced $\square$ Married

Figure 5 Difference of WTP medians among groups.

Notes: (A60) Self-vaccinated WTP for adults without children* for DV with 60\% efficacy for 10 years; (A90) Self-vaccinated WTP for adults without children for DV with $90 \%$ efficacy for 20 years; (P60) Self-vaccinated WTP for parents* for DV with 60\% efficacy for 10 years; (P90) Self-vaccinated WTP for parents for DV with $90 \%$ efficacy for 20 years; (C60) Vaccination WTP for children for DV with $60 \%$ efficacy for 10 years; (C90) Vaccination WTP for children DV with $90 \%$ efficacy for 20 years. *Parents are defined as those who have at least one child who is under 18. Adults are defined as those who have no children.

Abbreviations: DV, dengue vaccine; HCMC, Ho Chi Minh City; WTP, willingness to pay; GDP, Gross Domestic Product.

Indonesia, and US\$54.05 in Brazil). As predicted, the higher the first bid is, the higher the customer is willing to pay. This high starting point, at US\$234.78, was intentionally chosen based on: 1) experts' focus group discussions; 2) the highest prices in the latest studies in Vietnam; ${ }^{15}$ and 3) the price offered by the first retailer in the Philippines market for a three-dose DV scheme in 2016 (12,000 Pesos). ${ }^{45}$

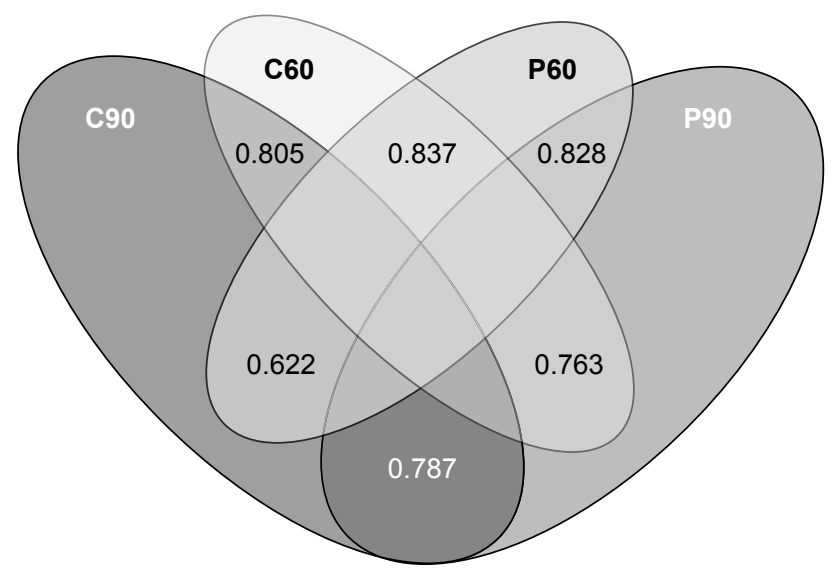

Figure 6 Venn diagram of significant Spearman's rank correlation coefficients between pairs of WTP.

Notes: (A60) Self-vaccinated WTP for adults without children* for DV with $60 \%$ efficacy for 10 years; (A90) Self-vaccinated WTP for adults without children for DV with $90 \%$ efficacy for 20 years; (P60) Self-vaccinated WTP for parents* for DV with $60 \%$ efficacy for 10 years; (P90) Self-vaccinated WTP for parents for DV with $90 \%$ efficacy for 20 years; (C60) Vaccination WTP for children for DV with $60 \%$ efficacy for 10 years; (C90) Vaccination WTP for children DV with $90 \%$ efficacy for 20 years. *Parents are defined as those who have at least one child who is under 18. Adults are defined as those who have no children.

Abbreviations: DV, dengue vaccine; WTP, willingness to pay.
Several methodological limitations should be noted. In addition to anchoring effect bias, the "social desirability bias" should also be considered, in which participants tend to give favorable answer to some questions. To minimize this bias, the 5-point Likert scale was preferred to dichotomouschoice questions. Nevertheless, this study only used 5-point Likert questions to evaluate the customer acceptance but not in the WTP sections due to time limits. Another bias to be considered is "compliance bias." This form of bias occurs when an interviewee decides to please the interviewer by overstating their WTP values. This study managed to reduce this type of bias by setting the participants a budget ceiling. Finally, given the scenarios, the WTP statements for DV in this study may not resemble the real-world values. Therefore, the pre-assigned scenarios were prepared based on the results extracted from the latest clinical trials on DV to determine both the efficacy and the protection duration.

Notwithstanding the limitations, the authors believe that this study is important because it is the first multicenter survey in southern Vietnam for DV and because it estimates the WTP for different DV scenarios among different population groups. The high medians of WTP, compared to the other studies, provide a key reference price for the introduction of DV in Vietnam. We encourage the Vietnamese authorities, vaccine manufacturers, and retailers to consult our findings on future pricing strategies and healthcare insurance policies. 


\section{Conclusion}

WTP rates and the number of participants who are willing to pay for DV were high in this study. These findings support the introduction of DV in Vietnam. This research also lays the foundation for broader assessment of WTP for different vaccination programs among various population groups in Vietnam.

\section{Acknowledgments}

The authors would like to acknowledge the volunteer participants for data collection. No funding was received for this analysis.

\section{Author contributions}

All authors contributed to data analysis, drafting or revising the article, gave final approval of the version to be published, and agree to be accountable for all aspects of the work.

\section{Disclosure}

The authors report no conflicts of interest in this work.

\section{References}

1. World Health Organization. Dengue and severe dengue; 2018. Available from: http://www.who.int/news-room/fact-sheets/detail/dengue-andsevere-dengue. Accessed September 20, 2018.

2. Murray NE, Quam MB, Wilder-Smith A. Epidemiology of dengue: past, present and future prospects. Clin Epidemiol. 2013;5:299-309.

3. Bhatt S, Gething PW, Brady OJ, et al. The global distribution and burden of dengue. Nature. 2013;496(7446):504-507.

4. Stanaway JD, Shepard DS, Undurraga EA, et al. The global burden of dengue: an analysis from the Global Burden of Disease Study 2013. Lancet Infect Dis. 2016;16(6):712-723.

5. Vietnam Ministry of Health-General Department of Preventive Medicine. Dengue fever in 2018; 2018. Available from: http://vncdc.gov. $\mathrm{vn} / \mathrm{vi} /$ tin-tuc-trong-nuoc/2354/cong-van-bo-y-te-gui-giam-doc-so-yte-cac-tinh-thanh-pho-tiep-tuc-day-manh-cong-tac-phong-chong-dichbenh-mua-he-thu-nam-2018. Accessed September 20, 2018.

6. World Health Organization (WHO). Guidelines for Diagnosis, Treatment, Prevention, and Control. Geneva: WHO; 2009.

7. World Health Organization (WHO). Handbookfor Clinical Management of Dengue. Geneva: WHO; 2012.

8. Larson HJ, Jarrett C, Eckersberger E, Smith DM, Paterson P. Understanding vaccine hesitancy around vaccines and vaccination from a global perspective: a systematic review of published literature, 2007-2012. Vaccine. 2014;32(19):2150-2159.

9. Schwartz LM, Halloran ME, Durbin AP, Longini IM. The dengue vaccine pipeline: implications for the future of dengue control. Vaccine. 2015;33(29):3293-3298.

10. World Health Organization. Dengue vaccine: WHO position paper July 2016. Wkly Epidemiol Rec. 2016;91(30):349-364.

11. Bloom DE, Fan VY, Sevilla JP. The broad socioeconomic benefits of vaccination. Sci Transl Med. 2018;10(441):eaaj2345.

12. Shepard DS, Suaya JA, Halstead SB, et al. Cost-effectiveness of a pediatric dengue vaccine. Vaccine. 2004;22(9-10):1275-1280.

13. Deroeck D, Deen J, Clemens JD. Policymakers' views on dengue fever/ dengue haemorrhagic fever and the need for dengue vaccines in four Southeast Asian countries. Vaccine. 2003;22(1):121-129.
14. Amarasinghe A, Wichmann O, Margolis HS, Mahoney RT. Forecasting dengue vaccine demand in disease endemic and non-endemic countries. Hum Vaccin. 2010;6(9):745-753.

15. Lee JS, Mogasale V, Lim JK, et al. A multi-country study of the household willingness-to-pay for dengue vaccines: household surveys in Vietnam, Thailand, and Colombia. PLoS Negl Trop Dis. 2015;9(6): e0003810.

16. Hadisoemarto PF, Castro MC. Public acceptance and willingness-to-pay for a future dengue vaccine: a community-based survey in Bandung, Indonesia. PLoS Negl Trop Dis. 2013;7(9):e2427.

17. Godói IP, Santos AS, Reis EA, et al. Consumer willingness to pay for dengue vaccine (CYD-TDV, Dengvaxia ${ }^{\circledR}$ ) in Brazil; implications for future pricing considerations. Front Pharmacol. 2017;8:41.

18. Carlsson F, Johansson-Stenman O. Willingness to pay for improved air quality in Sweden. Appl Econ. 2000;32(6):661-669.

19. Corso PS, Hammitt JK, Graham JD. Valuing mortality-risk reduction: using visual aids to improve the validity of contingent valuation. J Risk Uncertain. 2001;23(2):165-184.

20. Cropper ML, Haile M, Lampietti J, Poulos C, Whittington D. The demand for a malaria vaccine: evidence from Ethiopia. J Dev Econ. 2004; 75(1):303-318.

21. Hammar H, Johansson-Stenman O. The value of risk-free cigarettes - do smokers underestimate the risk? Health Econ. 2004;13(1):59-71.

22. Hammit J, Graham J. Willingness to pay for health protection: inadequate sensitivity to probability? J Risk Uncertainty. 1999;8: $33-62$.

23. Johannesson M, Johansson P-O. Quality of life and the WTP for an increased life expectancy at an advanced age. J Public Econ. 1997;65(2): 219-228.

24. Krupnick A, Alberini A, Cropper M, et al. Age, health and the willingness to pay for mortality risk reductions: a contingent valuation survey of Ontario residents. J Risk Uncertain. 2002;24(2):161-186.

25. Liu JT, Hammitt JK, Wang JD, Tsou MW. Valuation of the risk of SARS in Taiwan. Health Econ. 2005;14(1):83-91.

26. Mahmud M. Contingent Valuation of Mortality Risk Reduction in Developing Countries: A Mission Impossible [Ph.D. dissertation]. Sweden: Gothenburg University; 2005.

27. Persson U, Norinder A, Hjalte K, Gralén K. The value of statistical life in transport: findings from a new contingent valuation study in Sweden. J Risk Uncertain. 2001;23(2):121-134.

28. General statistics office. Area, population and population density by province; 2016. Available from: https://www.gso.gov.vn/default. aspx?tabid=714. Accessed September 20, 2018.

29. Convention on the Rights of the Child. Archived October 31, 2010 at the Wayback Machine. The Policy Press, Office of the United Nations High Commissioner for Human Rights. New York: Convention on the Rights of the Child; 2010.

30. Lwanga SK, Lemeshow S. Sample size determination in health studies: a practical manual; 1991. Available from: http://www.who.int/iris/ handle/10665/40062. Accessed September 20, 2018.

31. Arredondo-García JL, Hadinegoro SR, Reynales H, et al. Four-year safety follow-up of the tetravalent dengue vaccine efficacy randomized controlled trials in Asia and Latin America. Clin Microbiol Infect. 2018; 24(7):755-763.

32. Guy B. Which dengue vaccine approach is the most promising, and should we be concerned about enhanced disease after vaccination? Questions raised by the development and implementation of dengue vaccines: example of the Sanofi Pasteur tetravalent dengue vaccine. Cold Spring Harb Perspect Biol. 2018;10(6):a029462.

33. Jackson LA, Rupp R, Papadimitriou A, Wallace D, Raanan M, Moss KJ. A phase 1 study of safety and immunogenicity following intradermal administration of a tetravalent dengue vaccine candidate. Vaccine. 2018; 36(27):3976-3983.

34. Yoon IK, Thomas SJ. Encouraging results but questions remain for dengue vaccine. Lancet Infect Dis. 2018;18(2):125-126. 
35. Sáez-Llorens X, Tricou V, Yu D, et al. Immunogenicity and safety of one versus two doses of tetravalent dengue vaccine in healthy children aged 2-17 years in Asia and Latin America: 18-month interim data from a phase 2, randomised, placebo-controlled study. Lancet Infect Dis. 2018; 18(2):162-170.

36. Malisheni M, Khaiboullina SF, Rizvanov AA, Takah N, Murewanhema G, Bates M. Clinical efficacy, safety, and immunogenicity of a live attenuated tetravalent dengue vaccine (CYD-TDV) in children: a systematic review with meta-analysis. Front Immunol. 2017;8:863.

37. Sáez-Llorens X, Tricou V, Yu D, et al. Safety and immunogenicity of one versus two doses of Takeda's tetravalent dengue vaccine in children in Asia and Latin America: interim results from a phase 2, randomised, placebo-controlled study. Lancet Infect Dis. 2017;17(6):615-625.

38. Dietrich EA, Ong YT, Stovall JL, Dean H, Huang CY. Limited transmission potential of Takeda's tetravalent dengue vaccine candidate by Aedes albopictus. Am J Trop Med Hyg. 2017;97(5):1423-1427.

39. Guy B, Briand O, Lang J, Saville M, Jackson N. Development of the sanofi pasteur tetravalent dengue vaccine: one more step forward. Vaccine. 2015;33(50):7100-7111.

40. Capeding MR, Tran NH, Hadinegoro SR, et al. Clinical efficacy and safety of a novel tetravalent dengue vaccine in healthy children in Asia: a phase 3, randomised, observer-masked, placebo-controlled trial. Lancet. 2014;384(9951):1358-1365.
41. Guy B, Barrere B, Malinowski C, Saville M, Teyssou R, Lang J. From research to phase III: preclinical, industrial and clinical development of the Sanofi Pasteur tetravalent dengue vaccine. Vaccine. 2011;29(42): 7229-7241.

42. Fajar JK, Harapan H. Socioeconomic and attitudinal variables associated with acceptance and willingness to pay towards dengue vaccine: a systematic review. Arch Clin Infect Dis. 2017;12(3):e13914.

43. Harapan H, Anwar S, Bustamam A, et al. Willingness to pay for a dengue vaccine and its associated determinants in Indonesia: a communitybased, cross-sectional survey in Aceh. Acta Trop. 2017;166:249-256.

44. Haab TC, McConnell KE. Valuing Environmental and Natural Resources: The Econometrics of Non-Market Valuation. Cheltenham: Edward Elgar; 2002.

45. Kathrivera.com. Dengvaxia dengue vaccine now available in Watsons; 2017. Available from: http:/www.kathrivera.com/2017/04/ dengvaxia-dengue-vaccine-now-available-in-watsons.html. Accessed September 20, 2018

46. The World Bank. GDP per capita (current US\$); 2018. Available from: https://data.worldbank.org/indicator/ny.gdp.pcap.cd?locations=vn Accessed June 5, 2018.

47. Pham LD, Phung NH, Le NT, Vo TQ. Economic report on the cost of dengue fever in Vietnam: case of a provincial hospital. Clinicoecon Outcomes Res. 2017;9:1-8.
Patient Preference and Adherence

\section{Publish your work in this journal}

Patient Preference and Adherence is an international, peer-reviewed, open access journal that focuses on the growing importance of patient preference and adherence throughout the therapeutic continuum. Patient satisfaction, acceptability, quality of life, compliance, persistence and their role in developing new therapeutic modalities and compounds to optimize

\section{Dovepress}

clinical outcomes for existing disease states are major areas of interest for the journal. This journal has been accepted for indexing on PubMed Central. The manuscript management system is completely online and includes a very quick and fair peer-review system, which is all easy to use. Visit http://www. dovepress.com/testimonials.php to read real quotes from published authors. 